\section{O pior exemplo: uma análise fílmica de Drácula 3000}

The worst example: an film analysis of Dracula 3000

\section{Victor Finkler Lachowski}

Universidade Federal do Paraná. Departamento de Comunicação Social.

\section{Osmar Serafin Buzinhani Filho}

Universidade Federal do Paraná. Departamento de Comunicação Social.

\section{Lucas Matsumura}

Universidade Federal do Paraná. Departamento de Comunicação Social.

\section{RESUMO}

Este artigo realiza uma análise fílmica da obra Drácula 3000 (ROODT, 2004). Para isso, discute-se a presença de mitos e seu realocamento da cultura pop para outra temporalidade sob uma lógica capitalista, as narrativas de ficção científica e a relação entre os mitos e os arquétipos presentes nos personagens da trama. Como resultado, foi observado que a criação da obra parte de uma lógica mercadológica capitalista, que reconta mitos por meio de personagens baseados em arquétipos, visando

\section{ABSTRACT}

This article performs a film analysis on the work Dracula 3000 (ROODT, 2004). For this purpose, it discusses the presence of myths and its relocation from pop culture to a new temporality under a capitalist logic, Sci-fi narratives and the connection between myths and archetypes in the characters' plot. As a result, it shows a market-oriented logic under its development, that recapitulates myths through archetypebased characters, eyeing profit with cultural production. In that regard, ao lucro com uma produção cultural. Assim, os mitos continuam vivos dentro da cultura e do conhecimento popular. Também foi concluído que o conteúdo do filme pertence principalmente ao gênero da ficção científica, porém utiliza diversos elementos da fantasia como suporte para justificar sua trama, além de diálogos com o terror e a ação para auxiliar a direção e as decisões de roteiro.

PALAVRAS-CHAVE: Drácula 3000; Análise Fílmica; Mitos; Cultura Pop; Transtemporalidade Mítica; Arquétipos. myths stay alive inside culture and popular knowledge. Another conclusion was that the film content majoritarily fit into the Sci-fi genre, despite utilizing several elements from fiction to justify itself, as well as dialogues between horror and action to facilitate direction and plot decisions.

KEYWORDS: Dracula 3000; Film Analysis; Myths; Pop Culture; Mythical Trans-temporality; Archetypes. 


\section{INTRODUÇÃO}

Para se analisar Drácula 3000 (ROODT, 2004), é necessário um resumo do enredo da obra a partir de sua sinopse: a trama se passa no espaço sideral do ano 3000 d. C., quando a nave de resgate Mãe III, comandada pelo Capitão Van Helsing (Casper Van Dien), detecta uma espaçonave abandonada em seus sensores. Para buscar e embolsar cargas de valor, os tripulantes decidem rebocála de volta à Terra, mas ela se desacopla e começa a vagar pelo espaço. No meio dessa operação, Conde Drácula ressurge das trevas para aterrorizar a tripulação espacial que, ao mesmo tempo, tenta descobrir o que aconteceu com a nave e busca formas de combater a presença maligna mais famosa dos vampiros (ADOROCINEMA, 2004).

Lançado em 4 de dezembro de 2004, Drácula 3000 ficou conhecido por ser um filme trash ou $Z$, termos que remetem a um grupo de filmes de baixo orçamento e de qualidade duvidosa. O longa é uma produção norte-americana e sul- africana, e possui uma hora e vinte seis minutos de duração. Em agregadores de críticas cinematográficas na internet, o filme costuma ocupar listas de "piores filmes da história" e conta com avaliações extremamente baixas. Seguem alguns exemplos ${ }^{1}$ :

1. IMDb (/nternet Movie Database): apresenta uma nota 2.1, significando a média das avaliações de 1 a 10 dadas pelos usuários do site;

2. TMDB (The Movie Database): apresenta uma nota de $26 \%$, sendo essa similar ao sistema do IMDb, mas em porcentagem;

3. Letterboxd. apresenta uma nota de 1.3, média das avaliações dos usuários de 1 a 5;

4. Rotten Tomatoes. apresenta uma nota 1 de 5 na avaliação dos críticos (média de duas notas 1 no total, o que o site considera como "sem consenso"). A avaliação dos usuários fica em 15\%².

Apesar de suas péssimas qualidades, incluindodireção, roteiro,cinematografia, atuações, produção de cena, maquiagens e figurinos, o filme é conhecido por transportar uma narrativa pop e, com pequenas inspirações históricas (Conde Vlad da Romênia), inserir o vampiro mais famoso do mundo para um ambiente unusual: o espaço sideral em quase mil anos no futuro.

O impulso para adaptar a história do vampiro Drácula no cinema surgiu do livro homônimo, lançado originalmente em 1897 por Bram Stoker (1847 - 1912). Em 1922, o livro foi adaptado e recebeu outro título, o clássico Nosferatu (1922), o qual é um dos marcos da história do cinema e foi refilmado em 1979. Em 1958, Christopher Lee (1922 - 2015) interpretou o vampiro pela primeira vez, e repetiu o papel em mais sete ocasiões. Francis Ford Coppola (1939 - ) dirigiu a versão cinematográfica definitiva, Drácula de Bram Stoker (1992), que trouxe Gary Oldman (1958 - ) imortalizado como Conde Drácula. A última grande produção em cinema sobre o vampiro foi Drácula: a história nunca contada (2014), alvo de inúmeras críticas negativas e de fraca bilheteria. Além da presença no cinema, o vampiro já passou por desenhos animados, HQs, gibis, livros, novelas, etc., sendo uma das criaturas do terror mais populares e disseminadas pela cultura pop.

Dessa forma, é interessante o questionamento de como a imagem do Drácula se tornou um mito que se disseminaria através da cultura, chegando na indústria cinematográfica atual. Drácula 3000é uma das adaptações que tem como objetivo reutilizar personificações já consolidadas e inserilas em novos contextos. No final do ano de 2000, por exemplo, quatro anos antes de Drácula 3000, o diretor Patrick Lussier (1964 - ) lançou Drácula 2000 (2000), filme que colocou a figura do vampiro na contemporaneidade. Embora não tenha recebido críticas tão duras quanto seu sucessor futurista, suas notas em agregadores, assim como de suas duas sequências, são igualmente baixas. Portanto, o objetivo deste artigo é compreender os elementos presentes 
em Drácula 3000 que merecem atenção para serem pesquisados. Para isso, utiliza-se a análise fílmica (VANOYE; GOLIOT-LÉTÉ, 2002) para a descoberta de significados dentro da obra e para entender como se desenvolve a imagem do vampiro no cinema contemporâneo. Assim surgiu esta pesquisa, referente à temporalidade, à mitologia, à cultura pop e aos arquétipos presentes dentro do filme.

Com o intuito de realizar uma análise dessas temáticas em Drácula 3000, foi necessário ter como parâmetros determinadas concepções teóricas que permitam o estudo. Para entender a imagem do Drácula como um mito repassado pela cultura, com elementos sendo adaptados e transformados ao longo de diferentes contextos, foram utilizadas as definições de mito de Mano, Corso e Weinmann (2018), e as conceituações de mito e cultura de Camargo (2013). Para explicar como os mitos são adaptados na contemporaneidade em produções culturais, por meio da cultura pop, foram coletadas argumentações de Castro (2015), com os apontamentos de Conter, Telles e Araujo (2015) para revelar o papel mercadológico do capitalismo em recontar mitos com novas roupagens.

Para compreender o aspecto conteudista do filme quanto ao seu gênero, ou melhor, gêneros cinematográficos, foram trazidas as definições de ficção científica, fantasia, terror e ação propostas por Nogueira (2010). Para aprofundar o debate sobre a ficção científica em Drácula 3000, gênero identificado como o principal da obra, foi analisado se seu conjunto de recursos fílmicos (roteiro, direção, montagem, cinematografia, direção de arte, etc.) se enquadra nas 5 fases da ficção científica de Santana (2015).

Na última etapa do desenvolvimento desta pesquisa, são apresentadas as formas pelas quais foram construídas a trama e a concepção dos personagens de Drácula 3000, a partir de abstrações universais que regem o inconsciente coletivo, definidas por Jung (2000) e Anaz (2020) como arquétipos. Para intercalar a presença de figuras míticas e arquetípicas em estruturas narrativas, são introduzidas ideias de Campbell (1997) e Vogler (2006), os quais também são utilizados para classificar os personagens do filme analisado dentro de certos padrões propostos.

\section{METODOLOGIA}

Para elaborar uma pesquisa coerente aos temas citados, foram utilizadas duas metodologias que se complementam. Primeiro, uma revisão bibliográfica feita após assistir ao filme, referente aos temas de interesse levantados. Nessa etapa, coletamos percepções e textos acadêmicos referentes aos assuntos ligados à mitologia, à cultura pop e aos arquétipos que se encaixam na temática do Drácula 3000, que proporcionam uma gama de materiais e que permitam uma possível conclusão sobre o objeto de estudo.

Depois, foi feito o uso da análise fílmica de Vanoye e Goliot-Lété (2002), uma metodologia que permite o processo de desfragmentação textual do filme estudado. Para isso, ela requer o isolamento dos elementos de maior interesse do pesquisadoreoalinhamento com a bibliografia buscada. Durante a análise fílmica, são situados os contextos e as variáveis de um filme, combinandoos com leituras e autores que permitem ao pesquisador reexaminar a obra de maneira aprofundada. No caso da presente pesquisa, mais do que ver ou rever Drácula 3000, foi possível estabelecer uma relação objeto-filme que revelou uma riqueza de elementos e de características pelo processo de desmonte da obra. Por se tratar de um filme rejeitado pela crítica e pelo público, seus detalhes e componentes fílmicos que valem o processo de estudo são ocultados pela crítica cinematográfica tradicional. Assim, esse método nos leva a usufruir de maneira ímpar uma obra considerada simplesmente como "ruim". Isso ocorre justamente pela maneira 
como a metodologia da análise fílmica trabalha o objeto, o fazendo se mover, de maneira a permitir aos pesquisadores moverem e mexerem seus significados e impactos (VANOYE; GOLIOT-LÉTÉ, 2002). Os autores dessa metodologia recomendam algumas regras, que proporcionam o uso correto da análise fílmica, as quais foram seguidas para elaboração do estudo de Drácula 3000. A primeira é o pesquisador (ou pesquisadores, como no caso desta análise) assistir várias vezes ao filme, para resultar em uma análise menos espontânea e mais controlada ao conteúdo observado. Isso é feito para o analista ser trabalhado, o fazendo realocar suas percepções e impressões sobre a obra e, assim, levantar hipóteses para serem consolidadas ou invalidadas (VANOYE; GOLIOT-LÉTÉ, 2002). Isso faz a análise fílmica ser vista como uma metodologia "visceral", uma vez que sua proposta é despedaçar, descosturar, desunir, extrair, separar, destacar e denominar materiais que não se percebem isoladamente "a olho nu". Diante dos conceitos estudados a partir da revisão bibliográfica, a última fase da análise fílmica consistiu em executar uma comparação entre os elementos observados no filme e os referenciais de estudos acadêmicos. O intuito dessa última parte foi compreender os elementos desconstruídos do filme a partir de uma ótica mais aprofundada, por meio dos estudos de Vanoye e Goliot-Lété (2002), e entender como se deu a elaboração da imagem do vampiro no filme Drácula 3000.

\section{DESENVOLVIMENTO}

\subsection{Mito e cultura pop}

Uma forma de se entender Drácula 3000 como um objeto de análise da ressignificação e da recontagem de mitos pela cultura pop é sua maneira de tratar o mito da figura do Drácula. Os mitos são entendidos como narrativas ou discursos que influenciam a cultura e são transportados através da historicidade por narradores, meios de comunicação e artes. Eles transpassam a temporalidade atual, como esclarecem Mano, Corso e Weinmann (2018). Assim, os mitos se mantêm vivos pela capacidade de serem repetidos e reimaginados, conservando a estrutura narrativa original que permite a adaptação e a alteração de detalhes específicos, se perpetuando e se renovando pelo tempo.

Com isso, pode-se dizer que o mito é historicizável, pois se permite ser convertido em uma narrativa remetida e localizada em uma temporalidade outra, ou seja, diferente da que foi concebida originalmente, e dá liberdade para o narrador ou espectador se inserir na história contada (MANO; CORSO; WEINMANN, 2018). O mito se apresenta como ficção justamente por possuir características ficcionais e por ter estabilidade e percepções individuais, o que resulta na sua definição de ficção coletiva.

Esse raciocínio pode ser complementado por Camargo (2013), que aponta o mito como "uma narrativa fantástica, impressionante e ainda viva no âmago humano" (p.54). Na perspectiva do autor, o cinema é uma mídia na qual os mitos se transmitem, ou melhor, se retransmitem, aproveitando o fato de esse meio ser um reforçador de subjetividades coletivas em que, inclusive, os arquétipos estão presentes.

Os mitos, além de influenciarem a cultura, também são transportados por ela. Ainda segundo Camargo (2013), a palavra cultura, por ser um conceito complexo, éabordada de várias maneiras dependendo da área de estudo, e pode ser entendida pela sua atribuição ao viés artístico, como referente às produções literárias, cinematográficas, musicais, teatrais ou circenses.

Dentro do espectro das "culturas" temos a "popular", constituída pelos saberes do povo. Esse conjunto de conhecimento similar também envolve o saber e a interpretação das narrativas e das ficções em que se inserem os mitos, por meio da cultura para as próprias produções culturais (MANO; CORSO; WEINMANN, 
Com o advento do capitalismo, pela cultura pop e acompanham as principalmente no ocidente, a transformações tecnológicas, sociais e conservação das narrativas ficou à culturais da sociedade e suas demandas. mercê dos processos midiáticos e Como justificam Conter, Telles e Araujo da reprodutibilidade comercial para (2015), com o avanço tecnológico do obtenção de lucro, o que ampliou o capitalismo e sua produção cultural, foi poder de penetração das narrativas criadoum repertório digital dememórias mitológicas nas produções artísticas e culturais, em que fica mais fácil ter acesso nos meios de comunicação. Isso torna a aos materiais de diferentes épocas e, cultura pop, no capitalismo, um campo com isso, a criatividade para transportar caracterizado pelaconstantemobilidade. histórias, roteiros, aventuras e narrativas É esse território móvel, transnacional para diversas ressignificações é e autorreferencial que constrói mídias incentivada. Uma vez que a cultura com perpetuações intergerações, e que cujo consumo não está delimitado a uma única camada social ou classe, elevando o nível de interatividade entre público e obra (MANO; CORSO; WEINMANN, 2018). E mais: "o pop seria uma prática cultural caracterizada pela presença de marcadores culturais, dentre os quais alguns dominantes e que se situam nesse espectro de temporalidade afeita ao quotidiano" (CASTRO, 2015, p.38), o queé um indício de que certas representações referenciais primordiais.

O processo de ressignificação dos mitos narrativos e de sua apropriação pelo capitalismo é bem visível em Drácula 3000. A proposta do filme é diretamente voltada em se apropriar da mitologia famosa e consolidada do vampiro, utilizando o nome de Drácula e de outros personagens relevantes desde sua gênese. Um exemplo é o famoso matador de vampiros, Van Helsing, que se torna o capitão da nave Mãe III, Abraham Van Helsing. O filme passa por realocação e ressignificação próprias para se enquadrar no gênero da ficção científica. Essa catarse mítica posiciona o acúmulo de passado mantido no original para o ano 3000, em um futuro inimaginável e com liberdade criativa para seus idealizadores (SANTANA, 2015). Com isso, fica mais nítida a relevância de se estudar o marco dos remakes e dos reboots nas recontagens das narrativas marcantes presentes na cultura $p o p$, e pode-se compreender melhor a perpetuação das estruturas mitológicas de origens antigas, às vezes desconhecidas, por meio de suas atualizações elaboradas ao longo da historicidade.

Mais amostras desses fenômenos são fornecidas ao longo da experiência fílmica de Drácula 3000. O nome dos personagens, suas funções e objetivos finais são realocados e se mantêm até certo ponto da trama, e o lugar geográfico da Transilvânia (região da Romênia) se transmuta em um planeta habitado por vampiros, dando, assim, sentido para tal local dentro da proposta da obra. Este é o efeito obtido ao desmaterializar e atemporalizar o mito (CONTER; TELLES; ARAUJO, 2015): desmaterializar ao remover os contextos originais dos conteúdos da narrativa e inseri-los em novas roupagens e acepções; temporalizar ao alocar tal história para um novo espaço temporal. Isso também é observável quando analisamos o comportamento, as crenças e as racionalidades dos personagens. Símbolos e credos tradicionais e 
difundidos há séculos, como a cruz, a noção do cristianismo e a concepção de Deus, são ilegais no ano 3000 d.C.e, como resultado, os personagens desconhecem as fraquezas clássicas dos vampiros. Para enfrentarem Conde Drácula e seus servos, os tripulantes devem entrar em contato com um passado distante e esquecido, e esse diálogo com o passado, presente desde o início do filme, é o que dá sentido, forma, desenvolvimento e conclusão ao filme.

A narrativa cinematográfica, no exemplo desta pesquisa, é utilizada em Drácula 3000 como uma forma de remake da história original do Conde Drácula. Isso é comum pois, como ressaltado anteriormente, a indústria cinematográfica capitalista reconta as mesmas tramas a partir de remakes, prequels, sequências, reboots e spinoffs. Para Conter, Telles e Araujo (2015), o repositório de dados digital do capitalismo, que permite o fácil acesso aos produtos culturais desenvolvidos, simplifica o processo de remoção de alguns desses de seus contextos originais para permitir realocações e desmaterializações que temporalizem suas propriedades narrativo-míticas em novos cenários.

A cultura necessita dessa redescoberta de materiais esquecidos ou localizados em círculos sociais limitados, para os atualizar e reinventar. Com novas roupagens, narrativas do passado retornam como elementos criativos novos, capitalizáveis, mercantilizados e, o mais importante, lucrativos (CONTER; TELLES; ARAUJO, 2015). Como exemplo do mito do Drácula, sua narrativa, seus valores, seus conteúdos e seus elementos não caíram no esquecimento ou nos nichos por serem perpetuados na cultura pop. Suas características e sua estrutura base seguem vivas e sendo recontadas em novas roupagens, estéticas e produções, com a benesse de processos de atualizações constantes. Drácula 3000 é um exemplo de produção cultural responsávelporrepassarummitoadiante, se aproveitando de suas características clássicas e impulsionando-as para um futuro distante, tanto em tempo quanto em espaço, e mesmo assim induzir o espectador a um sentimento de já visto e de pertencimento a um conjunto de ideias e elementos. Como diz Castro (2015): "sua temporalidade não tem angústia do tempo. Não compreende o tempo como um limite. É o modo do presente, da quotidianidade" (p. 39). Isso mostra a valorização e a exploração da originalidade dentro de uma mitologia já sabida popularmente de variadas formas.

\subsection{Ficção Científica}

Para categorizar Drácula 3000 em um ou mais gêneros cinematográficos, é necessário, antes de tudo, compreender que esses gêneros apresentam hibridismo e se apropriam de elementos uns dos outros para construírem novas possibilidades narrativas, ampliando a versatilidade e o instigamento dessas (SANTANA, 2015). No filme estudado, os principais, a priori, são a ficção científica, pois fabula fenômenos com o uso de conhecimentos científicos e de tecnologias que podem ser desenvolvidas em algum momento futuro; e o terror, por buscar o fascínio por meio do incômodo e do desconforto capaz de provocar em que assiste (NOGUEIRA, 2010).

Como o gênero central da obra é a ficção científica, pode-se analisar como esse filme se enquadra dentro das 5 fases da ficção científica, elaboradas por Santana (2015):

1a Fase: Trabalha a narrativa a partir do maravilhoso (que causa assombro) e dos impactos deste para a humanidade; $2^{a}$ Fase: Constrói as narrativas envoltas de uma cientificidade que direciona os rumos da humanidade;

3a Fase: Estabelece a inserção de um modo fabular à ficção científica;

4ª Fase: Planta os padrões narrativos decorrentes da presença desses aparatos tecnológicos ficcionais;

5a Fase: Mescla o legado do gênero e da narrativa da obra com 
os artifícios visuais e sonoros, criados para representar e imprimir imersão no espectador enquanto simultaneamente são misturadas as quatro fases anteriores. Dessa forma, o filme é desconstruído por uma análise dentro do seu próprio gênero principal e analisado quanto à correspondência às 5 fases e a outras características da ficção científica. Importante ressaltar que essas fases se apresentam embaralhadas e mescladas, não estando necessariamente em ordem, mas, sim, dentro da miscelânea que compõe uma obra cinematográfica. Na análise do filme, foi observado que ele se encaixa nessas 5 fases com facilidade:

1aFase:Otrabalhodo"maravilhoso", da "surpresa", acontece com a introdução da nave abandonada logo no início, quando os tripulantes da Mãe III entram no veículo espacial fantasma e se deparam com situações inexplicáveis, como cadáveres segurando crucifixos, e começam a criar suspeitas e teorias quanto ao que aconteceu com a nave e com o que estava sendo transportado na carga abandonada.

2a Fase: O trabalho da narrativa por meio da cientificidade se dá pelo uso do próprio tempo em que o filme se passa. Conceitos comoviagensinterplanetárias, passando por diferentes sistemas solares, e o uso de aparatos avançados e de termos científicos inexistentes na atualidade inserem o espectador dentro do recorte temporal em que se transmite a película.

3a Fase: A introdução do modo fabular dentro da ficção científica acontece na trama que dá nome ao filme, na qual o elemento vampiresco, bem como a mitologia (família Van Helsing, modos de matar e espantar um vampiro) vão se tornando mais evidentes e presentes. A concepção de algo além do lógico, que precisa ser enfrentado usando até mesmo a fé e a religião, traz uma interrupção da ciência e da lógica antes vigentes no filme.

4a Fase: A trama é resolvida utilizando a tecnologia e, no caso do filme, direcionando a nave para a estrela mais próxima a fim de que sua luz mate o vampiro. Assim, o aparato tecnológico se alinha com a lenda sobrenatural e sombria do vampiro para a solução do problema inicial.

5a Fase: A utilização técnica de imagens e sons, tanto com efeitos computadorizados quanto com efeitos práticos, se mistura aos elementos das fases anteriores para que a junção de todas elas construa o tecido fílmico.

Juntas, essas fases exercem vários aspectos da ficção científica contemporânea, em que os personagens e seus dramas "perdem força para o efeito científico e acabam por deslocar o eixo narrativa do drama humano para um espaço narrativo que deixa em segundo plano o drama individual de cada personagem" (SANTANA, 2015, p. 155-156).

Retornando à 3a fase, o modo "fabular" dentro da ficção científica se relaciona bem com o gênero, uma vez que os tipos de saber (religioso e científico) podem apresentar proximidades e diálogos em suas abordagens, com ambos tendo os mesmos objetivos: dar respostas e projeções sobre fenômenos, ações e possíveis futuros para a humanidade (NOGUEIRA, 2010). A fantasia é, então, um gênero essencial para o uso da ficção científica no objeto estudado, pela forma como traz à tona essas formas de conhecimentos místicos, religiosos e fabulares, e como sustenta seu plot em uma mitologia abundante em conceitos e concepções.

Nogueira (2010) justifica que, na ficção científica, as religiões e as magias, que dominaram os discursos e as crenças sociais da humanidade, são substituídas pela tecnologia e pela racionalidade lógica, uma vez que a ciência desmistifica e esclarece os fenômenos. Como explicado, o futuro do filme deixa isso notável, com os conhecimentos e desconhecimentos dos personagens, sem nenhuma noção de messianismo, divino e profano. Isso reforça a classificação do filme no gênero.

Para encerrar o tópico, a ficção científica 
do filme também dialoga com outros dois gêneros: o terror e a ação. O terror por apresentar a angústia advinda da ameaça da criatura sobrenatural e racionalmente incompreensível do vampiro. Já a ação está nas cenas de batalha, no uso de equipamento bélico e na coreografia de lutas de artes marciais e de autodefesa, recursos usados tanto pelos mocinhos quanto pelos vilões na tentativa de subjugar uns aos outros.

\subsection{Arquétipos junguianos e a Jornada do Herói}

O conceito de arquétipos pode ajudar na compreensão de como os personagens de Drácula 3000 foram concebidos e de quais ideias as suas personalidades passam aos espectadores. Em remakes como esse, e no cinema dito mainstream em geral, que abarca um grande orçamento disponível para produções feitas para a obtenção de um lucro massivo, os arquétipos são vitais para o desenvolvimento de personagens carismáticos e completos que cativem o público, resgatando a ideia dos mitos. Essa escolha de roteiro, dentro da cultura pop,

explora de forma pragmática as adaptações do conceito junguiano, a partir principalmente das obras 0 herói de mil faces (1997), de Joseph Campbell [1904 - 1987], com sua teoria da "jornada do herói", ou "monomito", e $A$ jornada do escritor (2006), de Christopher Vogler [1949 -], que desenvolve uma espécie de guia para roteiristas (ANAZ, 2020, p. 253, comentários nossos).

A ideia dos arquétipos remonta ao mundo das ideias de Platão (428/427 a.C. - 348/347 a.C.), que ressoou em muitos outros filósofos como Immanuel Kant (1724 - 1804), até chegar no que foi formulado pelo psicólogo suíço Carl Jung (1875 - 1961), apesar de o conceito junguiano de arquétipo ser bem diferente do de seus antecessores. Jung pensa os arquétipos como órgãos psicológicos do cérebro humano que, dentro do inconsciente, demarcam características comuns a todos os indivíduos e agem como mitos que antropomorfizam a realidade (JUNG, 2000). Em suma, eles funcionam como motivos inconscientes, mas coletivos, para as ações dos personagens, e são facilmente identificáveis e formulaicos, uma forma prática de construção literária.

Isso ocorre, pois ao se deparar com o arquétipo, "a mente humana (em sua parte inconsciente) abriga imagens primordiais, universais e a-históricas que operam na psique e resultam em padrões de comportamento suprapessoais" (ANAZ, 2020, p. 255, grifos do autor). Entretanto, Jung difere o arquétipo da ideia de mito. O arquétipo está presente na criação mitológica, porém é visto como uma reação psicológica mais imediata do que as elaborações conscientes historicamente concebidas que a definem. Nas palavras do autor:

Sua manifestação imediata, como a encontramos em sonhos e visões, é muito mais individual, incompreensível e ingênua do que nos mitos, por exemplo. O arquétipo representa essencialmente um conteúdo inconsciente, o qual se modifica através de sua conscientização e percepção, assumindo matizes que variam de acordo com a consciência individual na qual se manifesta. (JUNG, 2000, p. 17).

Como conceitos pré-concebidos, os arquétipos tiveram um papel fundamental nos mitos de criação e na tradição, por exemplo. Então, é impossível pensar na produção cultural histórica do ser humano sem sua presença. Os padrões cognitivos podem ser encontrados em diversas culturas completamente autônomas entre si (ANAZ, 2020).

As fases da ficção científica não fogem dessa lógica em sua construção de roteiro e de personagens, e o gênero não está livre do monomito, conceito retratado na obra de Joseph Campbell (1997). 
para que os personagens de Drácula 3000 possam ser descritos na lógica arquetípica junguiana. Campbell (1997) e Vogler (2006) deixaram as ideias de Jung mais palatáveis para o estudo do cinema e para a identificação dos atores da construção de personagens. Campbell (1997) fala da Jornada do Herói entendendo que toda a mitologia, sendo mitos de criação, filosofia, religião e artes, funcionam dentro do círculo básico do mito - o que significa que são inspirados por ele e se encontram dentro do limite da atividade da mente humana (CAMPBELL, 1997). Toda história contada que contém um herói, desde Prometeu, Moisés e Buda até os dias de hoje, com personagens como Frodo, Beatrix Kiddo e Harry Potter, abusam da Jornada do Herói e de suas fases e componentes.

É claro que a história de Moisés não é minuciosamente igual à da Noiva de Kill Bill (TARANTINO, 2003), mas, como os mitos são historicizados e mutáveis ao longo do tempo, os arquétipos e a Jornada do Herói também encontram-se em um espaço no qual "cada contador de histórias adapta o padrão mítico a seus propósitos ou às necessidades de sua cultura" (VOGLER, 2006, p. 35). Isso seria o conceito do livro de Christopher Vogler, O Herói de Mil Fases, em que ele realizou uma análise mais compacta e realmente formulaica para $\mathrm{o}$ ato da escrita, ao reverenciar a obra de Campbell. Para Vogler (2006), a Jornada do Herói é composta de doze fases. São elas: o mundo comum; o chamado à aventura; a recusa do chamado; o encontro com o mentor; a travessia do primeiro limiar; testes, aliados, inimigos; a aproximação da caverna oculta; a provação; a recompensa; o caminho de volta; a ressurreição; o retorno com o Elixir (VOGLER, 2006, grifo nosso).

Nas doze fases, pode-se encontrar o monomito,ashistóriassempreserepetem de acordo com a lógica separaçãoiniciação-retorno (CAMPBELL, 1997). Ele descreve essa "unidade nuclear" da mitologia como "um afastamento do mundo, uma penetração em alguma fonte de poder e um retorno que enriquece a vida." (CAMPBELL, 1997, p. 20).

Em relação com o esquema de Vogler (2006), a separação pode ser encontrada no chamado à aventura, em que o herói encontra-se fora de seu mundo comum e vê-se num local hostil e diferente. Podemos pensar na primeira ida de Harry Potter à Hogwarts, em Harry Potter e a pedra filosofal (COLUMBUS, 2001), ou no filme aqui analisado, quando os personagens saem do conforto da Mãe III eadentramanaveespacialdesconhecida. A iniciação pode ser entendida como toda fase posterior ao encontro com o mentor: os testes, inimigos, a provação etc., pois é o que cria o conflito e onde reside o climax da história. Nesse caso, ela pode ser entendida como o descobrimento do Drácula e, citando caso análogo, a jornada enfrentada por Frodo após a missão da destruição do anel dada pelo mentor Gandalf em $O$ senhor dos anéis: a sociedade do anel
(JACKSON, 2001). Por último, o retorno é a resolução. Quando o herói completa sua jornada, ele supera seus problemas internos (da psique) e torna-se o herói de facto, retornando ao seu local de origem com uma recompensa, com seu dever cumprido ou com um maior conhecimento (o que seria, dentro da análise de Vogler (2006), o retorno com o Elixir). Por exemplo, quando Sen resgata seu nome verdadeiro em $A$ viagem de Chihiro (MIYAZAKI, 2001). Em Drácula 3000 , o retorno estaria entre o sacrifício de Van Helsing e a nave colidindo no sol. O monomito também possui outras características marcantes que se encontram presentes em Drácula 3000. Há uma figura de "monstro-tirano", uma transformação do mundo comum (o fim da presença maligna de Drácula) e um herói que supera suas limitações e que se sacrifica pelo seu ideal, além de possuir dons considerados divinos. Essas ideias que encontradas em todas as narrativas podem ser entendidas como diversos personagens, mas que não são 
fechados dentro de si, já que são mais bem representados como facetas do próprio herói - mutáveis, como máscaras que desempenham funções. Por isso, é normal que certo personagem tenha múltiplos papéis na jornada. As máscaras de Vogler (2006) dividem-se nos seguintes arquétipos: Herói, Mentor ou Velho Sábio, Guardião de Limiar, Arauto, Camaleão, Sombra e Pícaro.

\subsection{Os arquétipos em Drácula 3000}

Van Helsing é tido na trama como descendente direto do personagem Abraham Van Helsing, o caçador de vampiros do Drácula de Bram Stoker (2018 [1897]). Ele é alvo da ira e da vingança do Conde Orlock e a razão para o vampiro ter retornado de seu sono (embora o filme não explique como o encontro entre os dois foi proposital). Ele se posiciona no ranque mais alto entre os tripulantes, dita as ações de todos e confere todas as decisões antes de serem deferidas. Van Helsing é claramente o Herói desse filme, pois é "alguém que está disposto a sacrificar suas próprias necessidades em benefício dos outros" (VOGLER, 2006, p. 52). Incorporando as partes de si mesmo divididas entre os outros arquétipos, o Herói possui algumas funções dramáticas específicas. A primeira delas é a identificação com a plateia, à medida que o desejo de sucesso e de ser amado pelos outros é uma qualidade universal - seria natural, então, que o Herói fosse a pessoa em que o público depositará suas esperanças e vivências durante a experiência cinematográfica. O Herói também é sempre o mais ativo do roteiro, fato evidente na película, e precisa lidar com a morte: "No âmago de toda história existe um confronto com a morte." (VOGLER, 2006, p. 54). Essa, presente como ameaça de morte real no confronto com Drácula e simbólica em sua relação afetuosa com Aurora e os demais membros da equipe. Vogler (2006) aponta que os heróis "orientados para o grupo", como Van Helsing tem de optar entre o retorno ao "Mundo Comum" e a permanência no
"Mundo Especial" e, em Drácula 3000, a escolha é a permanência na forma de sacrifício, outra característica desse arquétipo (VOGLER, 2006). Isso difere de outras edições com a mesma mitologia, pois Van Helsing não derrota o vilão, tornando-se mártir e mito inspirador.

A sua ascendência da personagem original também não pode ser ignorada. O Herói simboliza "aquela divina imagem redentora e criadora, que se encontra escondida dentro de todos nós e apenas espera ser conhecida e transformada em vida" (CAMPBELL, 1997, p. 21), o que faz com que o público torça para seu sucesso por recognição. O capitão da nave resgata "os poderes divinos, procurados e perigosamente obtidos" dos seus antepassados que "sempre estiveram presentes no coração do herói" (CAMPBELL, 1997, p. 21). Campbell (1997) traz a ideia do "filho do rei" para descrever essa predestinação divina, aqui ele é o "filho de Van Helsing" e deve agir de acordo. É assim que seu protagonismo é justificado.
Outro personagem é O Professor, que se enquadra no arquétipo do Sábio, ou do Mentor. Ele sempre digita rapidamente nos computadores, utiliza óculos e se locomove em uma cadeira de rodas, reforçando estereótipos de pessoas muito inteligentes. É o personagem que mais tem autonomia no grupo e essa característica, que pode ser tida como heroica, pode ser explicada por três motivos. Na análise arquetípica, Arthur foge do mentor comum, o que guia o herói para a aventura, apesar de ter informações privilegiadas (notoriamente o conhecimento de religião, embora o filme indique que nenhum resquício de cristianismo existia naquela sociedade há milênios). Assim, além de representar o self, como tido por Jung (2000) e Vogler (2006), ele caracteriza-se como "mentor inventor" e presenteia o herói com "descobertas, planos ou invenções" (VOGLER, 2006, p. 64). Um bom exemplo desse tipo de Sábio é a figura de Alfred Pennyworth, o mordomo do super-herói Batman. 
Os outros dois motivos são a razão deste artigo tratar sobre Drácula 3000 e edificam-se em falhas de roteiro e em um desenvolvimento de personagem questionável. Imagina-se que um grupo de mercenários espaciais, como apresentado, conheça os termos básicos da pilotagem de naves ou que saibam ao menos o objetivo da missão, o que não acontece. O Professor, então, se acomoda nessa função de amenizar a parte cômica de uma maneira não intencional do roteiro. Por outro lado, pode pensar-se que não tinham tanta utilidade para a personagem somente e que seu sumiço da tela pela maior parte do filme caiu no pretexto de sua independência. Mesmo com a explicação de Vogler (2006) sobre a flexibilidade do arquétipo, e sobretudo desse arquétipo, não há uma boa razão para as funções flutuantes e irrelevantes d'O Professor.

Por outro lado, Aurora Ash pode ser entendida como um caos de personalidades, assim como O Professor, mas a história particular e os múltiplos plot twistse incongruências de suas falas a fazem a personagem mais complexa. A androide age de diversas formas no decorrer do filme, adotando diferentes máscaras, ainda mais quando revela aos seus companheiros ser uma espiã. Sem embargo, o arquétipo mais utilizado por Aurora é o do Camaleão, já que sua personalidade é confusa e pode estar em constante mudança, além de geralmente ser "o interesse amoroso do herói ou sua parceira romântica" (VOGLER, 2006, p. 78). Psicologicamente, é o ponto em que o espectador encontra dúvidas comuns aos seus relacionamentos: "Todos temos experiências de relações nas quais nosso parceiro é dúbio, tem duas caras, ou é espantosamente mutante" (VOGLER, 2006, p. 78). Por isso, Aurora carrega uma dualidade necessária para a Jornada do Herói, além de trazer a ideia de oposto dentro da dialética masculino/feminino, ela gera a desconfiança de todos quando revela ser uma espiã e é amarrada por Humvee.

Uma última reflexão sobre o fato de ela não ser humana remonta aos conceitos de robótica. Aqui, talvez os roteiristas tenham feito referência ao escritor americano Isaac Asimov (1920 - 1992) e às suas três leis da robótica, desenvolvidas ao longo de suas obras de ficção científica, para dar credibilidade ao gênero. Asimov (2014, p. 65) definiu a primeira diretiva como: "Um robô não pode ferir um ser humano ou, por inação, permitir que um ser humano sofra algum mal". Por exemplo, Aurora é altruísta, e quando é ordenada por Van Helsing a matar um dos vampiros que estavam dormindo nos caixões, a androide não é capaz de fazê-lo.

O personagem interpretado pelo rapper Coolio é diferente dos demais. 187 enquadra-se no arquétipo do Bobo da Corte ou do Pícaro, apresentando características de fora da lei, algo como um anti-herói. Desde a descrição dada sobre 187 no começo do filme, na qual é exposto que ele possui um Quociente de Inteligência de valor 187 e que começou a perdê-lo após entrar na universidade de Berkeley por "fumar tudo o que encontrava", o personagem exprime muito bem a posição. O Bobo da Corte tem duas características muito evidentes: a diversão inconsequente e a necessidade de enquadrar-se em um grupo - muitas vezes, rebaixando-se à humilhação para alcançar o segundo. Para Vogler (2006, p. 87), o Pícaro introduz "mudanças e transformações sadias, muitas vezes chamando a atenção para o desequilíbrio ou o absurdo de uma situação psicológica estagnada", algo cristalino em todo o decorrer do filme. $\mathrm{O}$ Bobo da Corte é uma figura importante para o herói, já que "Quando estamos nos levando demasiadamente a sério, a parte Pícaro de nossa personalidade pode surgir de repente para nos devolver a necessária perspectiva" (VOGLER, 2006, p. 87). Ademais, esse arquétipo é indispensável para o enredo de filmes de comédia e dentro da intergenericidade promovida pela ficção científica, além de ser presente na maioria dos filmes de terror ditos Trash ou B. 
187 também usa a máscara do Arauto, é fazer oposição ao herói, causando de uma maneira não-intencional, como muito do roteiro de Roodt e Milborrow. $\mathrm{O}$ Arauto desempenha a função de motivar e chamar à mudança, necessária para a conclusão da aventura heroica. Diz-se: "O Chamado pode vir de um livro que lemos, ou de um filme que vimos. Mas algo dentro de nós é tocado, como um sino que leva um golpe, e as vibrações resultantes espalham-se por nossa vida, até que a mudança seja inevitável" (VOGLER, 2006, p. 76). O Chamado, em Drácula 3000, aparece por conta do vício em inebriação descabida de 187, ao procurar drogas nos caixões da nave e começar de fato a história.

Porfim, Humvee é descrito no filme como alguém cuja única qualidade é ser forte. O personagem aparenta não possuir um arquétipo predominante. Na maioria das cenas, Humvee segue ordens do capitão Van Helsing e faz comentários inapropriados. A personalidade caótica e imprevisível de Humvee o qualifica como Sombra. A função do Sombra conflito. Ele faz com que Van Helsing tenha sua vida ameaçada e tenta trazer o melhor de dentro dele. Segundo Vogler (2006, p. 83), esse arquétipo representa "a energia do lado obscuro, os aspectos não-expressos, irrealizados ou rejeitados de alguma coisa". Para uma construção de personagem decente, os autores tentam humanizar ao máximo o Sombra e, em tramas mais complexas, os próprios vilões, algo que não é encontrado nem no "monstro-tirano" Drácula, nem em Humvee, o homem com nome de veículo militar. Ele torna-se o Herói no final, depois do sacrifício de Van Helsing, dirigindo a nave a caminho do sol (o final não é muito bem amarrado com a trama, então essa mudança completa na Jornada do Herói não fica tão descabida).

\section{CONSIDERAÇÕES FINAIS}

Drácula 3000é considerado um péssimo filme, tanto por avaliações de críticos especializados quanto pelo público geral. Apresenta críticas fundadas tanto no conteúdo em si quanto na filmografia e no desenvolvimento da trama e de seus personagens. Entretanto, até mesmo um filme não valorizado possui seu valor intelectual, o qual é comprovado na sua contribuição ao gênero do qual faz parte. Nessa análise, foi observado que ele se adapta de maneira adequada às 5 fases de Santana (2015), além de ter o uso do conhecimento científico para situar temporal e geograficamente a trama, requisito da definição do gênero para Nogueira (2010), o que conclui que esse é o gênero principal de Drácula 3000. Também foi observado que a obra recorreaos conceitos místicos e religiosos próprios do gênero cinematográfico da fantasia, uma vez que precisa inserir e desenvolver a mitologia do vampiro em seu decorrer, sendo essa mescla algo comum à ficção científica quanto gênero. Por fim, o terror e a ação contribuem com elementos de seus gêneros para escolhas de direção, manejo de cenas e andamento de roteiro.

A obra também revela os processos de transmissão dos mitos e dos arquétipos e como estes são empregados dentro da indústria cinematográfica sob a lógica capitalista. Assim, Drácula 3000, como outros filmes ou formas de expressão cultural, se utiliza de narrativas mitológicas populares para contálas sob novas roupagens. O resgate de Conde Drácula e de elementos de sua mitologia demonstram uma ação conjunta benéfica para a indústria cinematográfica e para os mitos: a indústria desenvolve produções culturais para obtenção de lucro e os mitos continuam sendo narrados adiante pela cultura pop (CONTER; TELLES; ARAUJO, 2015), mesmo que capitalizados em obras de baixo orçamento e de baixa qualidade. A mitologia também é mantida no conhecimento popular e seus produtos esperam futuras oportunidades para serem readaptados em novas fabulações. Exemplo disso é a constante propagação da Jornada do Herói no cinema e a relevância dada aos arquétipos pelos roteiristas e diretores 
na produção mainstream

Dada a relação entre o inconsciente coletivo do público e as imagens universais transmitidas, os elementos que compõem a trama são mais facilmente reconhecidos e, portanto, comercializáveis, mesmo em um filme com uma qualidade técnica inferior ao padrão vigente. A rápida identificação dos arquétipos do Arauto, do Pícaro e do Mentor, como aqui observado, não é negativa. O Herói sempre terá a história desenvolvida ao seu redor e suas máscaras idem. Entretanto, a caracterização de Drácula 3000 é tão exagerada que seus personagens caem em estereótipos, fugindo da relação saudável da fórmula de Vogler (2006) e Campbell (1997), tornando o filme cômico de maneira não proposital.

\section{NOTAS}

${ }^{1}$ Dados acessados em 18/08/2021.

${ }^{2}$ Críticas disponíveis em:

IMDB: https://www.imdb.com/title/tt0367677/

TMDB: https://www.themoviedb.org/movie/10838-dracula-3000

LETTERBOXD: https://letterboxd.com/film/dracula-3000/

ROTTEN TOMATOES: https://www.rottentomatoes.com/m/dracula_3000 


\section{REFERÊNCIAS FILMOGRÁFICAS}

A VIAGEM DE CHIHIRO. Direção: Hayao Miyazaki. Produção: Toshio Suzuki. Roteiro: Hayao Miyazaki. Intérprete: Joe Hisaishi. Japão: Studio Ghibli, 2001. (125 min.), son., color.

DRACULA 2000. Direção: Patrick Lussier. Produção: W. K. Border e Joel Soisson. Roteiro: Joel Soisson e Patrick Lussier. Intérprete: Marco Beltrami. 2000. (105 min.), son., color.

DRACULA 3000. Direção: Darrell Roodt. Produção: David Wicht. Roteiro: Ivan Milborrow e Darrell Roodt. Intérprete: Michael Hoenig. África do Sul: Film Afrika e Apollopromedia, 2004. (86 min.), son., color.

DRÁCULA: A História Nunca Contada. Direção: Gary Shore. Produção: Michael de Luca. Roteiro: Matt Sazama e Burk Sharpless. Intérprete: Ramin Djawadi. Estados Unidos: Legendary Pictures Michael de Luca Productions, 2014. (92 $\min$.), son., color.

DRÁCULA de Bram Stoker. Direção:
Francis Ford Coppola. Produção: Francis Ford Coppola, Fred Fuchs e Charles Mulvehill. Roteiro: James V. Hart. Intérprete: Annie Lennox e Wojciech Kilar. Estados Unidos: Columbia Pictures, 1992. (128 min), son, color.

HARRY POTTER e a pedra filosofal. Direção: Chris Columbus. Produção: David Heyman. Roteiro: J.K. Rowling e Steve Kloves. Música: John Williams. Estados Unidos, Reino Unido: Heyday Films, 1492 Pictures, 2001. (152 min.), son., color.

KILL BILL. Direção: Quentin Tarantino. Produção: Lawrence Bender. Roteiro: Quentin Tarantino e Uma Thurman. Intérprete:RZA.Estados Unidos:Miramax, A Band Apart, Super Cool ManChu, 2003. (111 min.), son., color.

NOSFERATU. Direção: F. W. Murnau. Produção: Albin Grau. Roteiro: Henrik Galeen. Alemanha: Prana-Film, 1922. (94 min.), $P \& B$.

O SENHOR DOS ANÉIS: A Sociedade do Anel. Direção: Peter Jackson. Produção: Peter Jackson. Roteiro: J.R.R. Tolkien, Fran
Walsh, Philippa Boyens e Peter Jackson. Intérprete: Howard Shore. Estados Unidos, Nova Zelândia: WingNut Films, The Saul Zaentz Company, 2001. (178 $\min$.$) , son., color.$

\section{REFERÊNCIAS BIBLIOGRÁFICAS}

ADOROCINEMA. Drácula 3000 Escuridão Infinita. 2004. Disponível em: https://www.adorocinema.com/filmes/ filme-145411/. Acesso em: 07 dez. 2020. ANAZ, Sílvio Antonio Luiz. Teoria dos arquétipos e construção de personagens em filmes e séries. Significação: Revista de Cultura Audiovisual, [S. I.], v. 47, n. 54, p. 251-270, 2020. Disponível em: https:// www.revistas.usp.br/significacao/ article/view/159964. Acesso em: 25 maio 2021.

ASIMOV, Isaac. Eu, Robô. $1^{\text {a }}$ edição. São Paulo: Editora Aleph, 2014.

CAMARGO, Hertz Wendel de. Mito

e filme publicitário: estruturas de significação. Londrina: EDUEL - Editora da Universidade Estadual de Londrina,
2013.

CAMPBELL, Joseph. 0 Herói de Mil Faces.

Trad. Adail Ubirajara Sobral. 10. ed. São Paulo: Cultrix/Pensamento, 1997

CASTRO, Fábio Fonseca de. Temporalidade e quotidianidade do pop. In: SÁ, Simone Pereira de; CARREIRO, Rodrigo; FERRARAZ, Rogério (orgs.).

Cultura Pop. Salvador/Brasília: EDUFBA/ Compós, 2015. p. 35-44.

CONTER, Marcelo Bergamin; TELLES, Marcio; ARAUJO, André. O Revirtual: a memória da memória na cultura pop. In: SÁ, Simone Pereira de; CARREIRO, Rodrigo; FERRARAZ, Rogério (orgs.). Cultura Pop. Salvador/Brasília: EDUFBA/ Compós, 2015. p. 93-108.

JUNG. Carl Gustav. Arquétipos e o inconsciente coletivo. Trad. Dora Mariana R. Ferreira da Silva e Maria Luiza Appy. 2. ed. Petrópolis: Vozes, 2000.

MANO, Gustavo; CORSO, Mário; WEINMANN, Amadeu de Oliveira. Psicanálise e cultura pop: os mitos no contemporâneo. Psicol. USP, São Paulo, vol. 29, no. 1, . p. 78-86, jan./abr. 2018. 
Disponível em: https://www.scielo.br/j/pusp/a/xHvhVQNxDN3Z65rMkbkJqrm/ abstract/?lang=pt. Acesso em: 17 nov. 2020.

NOGUEIRA, Luís. Manuais de cinema II: gêneros cinematográficos. 1. ed. Covilhã/ Portugal: LabCom Book, 2010.

SANTANA, Gelson. O líquido céu do futuro: o cinema de ficção científica na cultura pop. In:SÁ, Simone Pereira de; CARREIRO, Rodrigo; FERRARAZ, Rogério (orgs.). Cultura Pop. Salvador/Brasília: EDUFBA/Compós, 2015. p. 151-164.

STOKER, Bram. Drácula. Trad. Marcia Heloisa. Cajamar: Darkside, 2018.

VANOYE, Francis.; GOLIOT-LÉTÉ, Anne. Ensaio sobre a análise fílmica. Trad. Marina Apenzeller. 2. ed. Campinas: Papirus, 2002.

VOGLER, Christopher. A jornada do escritor: estruturas míticas para escritores. Trad. Ana Maria Machado. 5. ed. Rio de Janeiro: Nova Fronteira, 2006. 